\title{
Truth or Dare
}

\section{WHEN IT COMES TO DETECTING LIES, MANY INVESTORS DECEIVE THEMSELVES}

By Rhea Wessel

Fidgeting. Lack of eye contact. Nervous sweating. The person doing these things in front of you while telling a story must be lying. You can feel it, and now you have visible signs to back up your hunch.

Or could you be wrong?

Perhaps you have fallen prey to believing the advice you've read or seen on TV, provided by "experts" who promise to teach you how to discern truth from lies?

There's a whole industry built around lie detection that promises a quick fix, according to Maria Hartwig of City University of New York. "These experts say, 'Give me an hour

Contrary to popular belief, lies and dishonest behavior are difficult to detect.

Research indicates that investment professionals may be especially susceptible to deception because they are overconfident in their ability to detect lies.

Investors can learn to use more effective techniques, such as strategic use of evidence or linguistic inquiry, to improve their ability to identify deception. of your time at a hefty fee, and I will tell you magic insights about how you can become a better lie detector.' But it just doesn't work like that. That's charlatanry," she says.

Moreover, many investment professionals subscribe to common misconceptions about deceptive behaviorin particular, that liars are gaze averse and fidgetyaccording to recent research conducted by Hartwig, Jason Voss, CFA, and D. Brian Wallace. In their 2015 article "Detecting Lies in the Financial Industry: A Survey of Investment Professionals' Beliefs" (published in the Journal of Behavioral Finance and summarized in CFA Digest), they find that financial professionals may even be a little bit worse at detecting lies than other people.

"What analysts think they know about lie detection is wrong," says Voss, content director at CFA Institute. Moreover, financial professionals have a pronounced belief in their own capacity to detect lies, according to additional research conducted by Hartwig, Voss, Wallace, and Laure Brimbal, which is currently pending review by an academic journal. (The working title of the study is "Investment Professionals' Ability to Detect Deception: Accuracy, Bias, and Metacognitive Realism.")

This combination of low accuracy and high confidence means it's critical that financial professionals question their own abilities. In the end, it is the analyst's job to understand the reality of the situation as accurately as possible and discern truth from lies.

"In an ideal world, somebody who would be making judgments with less than $100 \%$ accuracy would express lower confidence in the judgments that turn out to be incorrect," Hartwig says. Yet their research shows no correlation between how sure a person was about being right and whether the person was actually right.

"Financial professionals have a lack of insight into whether they are wrong or right," says Hartwig. "That's problematic, because people are likely to act on judgments that they're highly confident about, but their feelings of confidence are not useful at all."

\section{TRUTH SEEKING}

If informed investors feel confident about a judgment but know this feeling may be caused by overconfidence, how can they trust their intuition enough to make a decision to act?

One approach would be to try factoring in average error rates in discerning truth from lies to achieve better accuracy, much as you might factor in well-known cognitive biases (such as anchoring, loss aversion, or the availability heuristic) when trying to assess certain situations. Or you could try to gain a better understanding of the psychology behind lying and truth telling.

On a more practical level, though, a better idea may be to adapt your approach to uncovering lies by adopting new questioning techniques when you suspect a lie.

\section{STRATEGIC USE OF EVIDENCE}

One such technique is the strategic use of evidence, in which an analyst strategically discloses what he or she knows in a sequenced manner so as to "catch" the other person in a lie. Voss supplies the following example: Imagine that an analyst says to a chief financial officer (CFO), "I noticed that your accounts receivables are building quite a bit relative to revenue growth. It seems to me that your new customers aren't highquality customers, and I think that's going to hurt margins."

That analyst just handed the CFO a key piece of evidence; in fact, this is the very point that the CFO should be disclosing to make the analyst believe she's telling the truth. "Not only did the analyst give away something strategically valuable in this example, he used the evidence in a non-strategic way," says Voss.

An alternative would be to start broadly_-by asking about economic trends in the region, for instance-and then to gradually narrow the context. "You would get answers from management without necessarily revealing the piece of evidence that you have. You put them on record with answers that later do not stand up against the piece of evidence you have," Voss says.

According to Voss, liars and truth-tellers differ in 


\section{Filling Knowledge Gaps}

Voss initiated the study into lie detection in the financial industry out of his desire to help investment managers make better qualitative decisions. A retired investment manager, Voss had looked back on his own experience and recalled how little literature was available to help him with the qualitative part of his job. "As content director at CFA Institute, I set out to fill some of those gaps and was interested in research into lies," Voss says.

That's when Voss came across a meta-analysis of research into lie detection written by Hartwig. Hartwig's research on interviewing to detect deception is groundbreaking and led her to testify before the US Congress in 2011, when she also challenged the work of Paul Ekman, a psychologist and professor who claims to be able to use body language to detect lies.

Both Voss and Hartwig say they had eye-opening experiences during their first meeting.

Voss was under the assumption that people can rely on body language to detect lies, and he found out that's not the case. Hartwig was surprised to find out that research into lie detection had not been applied to the financial industry at all.

"From my perspective," says Hartwig, "it was a pretty big revelation that there is this entire uncharted territory of application of the scientific literature. That's very exciting for me, because it suggests to me that you can conduct groundbreaking research because the questions are not even asked yet about lie detection in the financial industry."

Voss and Hartwig then designed a game plan: First, document the beliefs and assumptions held by people in the investment management profession (done in the first study and summarized in CFA Digest), then test those beliefs (done in the second and forthcoming study), and, finally, design tools to help investment professionals detect deception (forthcoming).

Looking back at the first study, Hartwig says she was also excited by the wide reach of the survey because of the large member base of CFA Institute. Some 607 CFA charterholders responded. "To my knowledge, apart from one other survey, this is the largest study ever conducted on beliefs about deception," she says.

"As a researcher," says Hartwig, "it was a huge treat to be able to deal with data of this quantity. We were also able to do something that rarely happens and that is to get a truly random sample. That gives us a much better sense that these are beliefs that are actually representative of the entire population of CFA charterholders." important ways. "Truth-tellers have no problem supplying answers, whereas liars have to be able to demonstrate to you that their version of reality is the correct one," he says. "Liars may change the subject or not answer the questions directly."

Hartwig adds, "A sequence of questions can be a test of what kind of mindset the person is in: 'Are you in the mindset of being forthcoming with me, or are you in a mindset of avoiding the things you think might be incriminating?"'

\section{LINGUISTIC INQUIRY AND WORD COUNT}

A second technique, linguistic inquiry and word count (LIWC), uses a computer to detect linguistic patterns, and not only those patterns linked to lying. For instance, LIWC has been used to analyze the similarities in language used among people who were on a first date and then began a relationship, the language used in successful job application letters, and even the linguistic patterns used in suicide letters.

To use LIWC to detect lying, financial professionals must learn the linguistic patterns of lying and train the LIWC software to detect the lies-e.g., to analyze a company's quarterly earnings conference call or written communications. LIWC can then create a statistical model and generate a probability that the statement is true or false, Hartwig explains.

An example of a linguistic pattern that may indicate lying is that liars tend to use more words or fewer first-person pronouns compared with truth-tellers.

\section{HIGHLIGHTS FROM PHASE TWO OF THE RESEARCH}

In the second study, Voss and Hartwig tested lies from companies' quarterly earnings or special announcement conference calls where the US Securities and Exchange Commission brought forth enforcement actions. Voss says, "The juicy bits here are that companies have incentives to fudge the record of business performance, such as the accounting, and that financial professionals are ill-equipped to be able to uncover a lie beyond financial statement analysis."

"For whatever reason, the lens through which analysts see the world is biased toward trusting," says Voss. "This is an important finding that financial professionals need to pay attention to."

This raises the question: Should investment professionals trust less in their ability to detect lies?

Yes, says Hartwig. "I sound like a broken record," she adds, "but I really want to emphasize that there aren't any quick fixes. Even people reading an

\section{KEEP GOING}

"Detecting Lies in the Financial Industry: A Survey of Investment Professionals' Beliefs," Journal of Behavioral Finance (vol. 16, no. 2); summarized in CFA Digest (January 2016) [www.cfapubs.org]

"May the Sorts Be with You," CFA Institute Magazine (May/June 2015) [www.cfapubs.org]

"Paying Attention-Literally," CFA Institute Magazine (March/April 2012) [www.cfapubs.org] article like this one won't be able to make more correct judgmentsbut perhaps their confidence in their skill will be tempered a bit."

Rhea Wessel is an American journalist, author, and speechwriter based near Frankfurt, Germany. 